\begin{tabular}{ccc}
\hline & International Journal of Engineering \& Technology, $7(2.23)(2018) 307-316$ \\
SPC & Website: $w$ ww.sciencepubco.com/index.php/IJET \\
Research paper & Technology \\
\hline
\end{tabular}

\title{
Features of the structure active centers of industrial catalysts for the oxidative chlorination of ethylene
}

\author{
Sergiy Kurta $^{1}$ *, Ihor Mykytyn ${ }^{1}$, Victoria Ribun ${ }^{1}$, Olga Khatsevich ${ }^{1}$ \\ ${ }^{1}$ Department of Chemistry, Vasyl Stefanyk Precarpathial Department of Chemistry, Vasyl Stefanyk Precarpathian National \\ *Corresponding author E-mail: kca2014@ukr.net
}

\begin{abstract}
The active phase of $\mathrm{CuCl} 2, \mathrm{HCuCl}, \mathrm{H} 2 \mathrm{CuCl} 4$ and two grades of industrial ethylene oxidation chlorination catalysts (EOC) such as deposited catalyst X1 (Harshow), with copper chlorides supported on an alumina surface, and a permeated MEDC-B catalyst immobilized in the internal pores of the firm of the company Sud-Chemie. Catalyst were analyzed by the method of thermoemission electronic raster (VEGA3NTSCAN) microscopy and X-ray fluorescence energy dispersion spectroscopy (EDX-7000). It is shown that the active catalyst centers of $\mathrm{CuCl} 2$ have different crystalline structure from the amorphous active phase of $\mathrm{H} 2 \mathrm{CuCl} 2, \mathrm{H} 2 \mathrm{CuCl} 4$ on the surface of the catalysts. On the surface of X1 Harshow copper chlorides are uniformly distributed throughout the volume of the carrier catalyst $\gamma$-Al2O3 in the form of amorphous portions [CuCl4]-2, [CuCl2]-1. At the same time, on the surface of the catalyst MEDC-B, the active centers have a separate cluster immobilized crystalline structure of the active phase, which differs from the composition of the carrier $\gamma$-Al2O3.
\end{abstract}

Keywords: Catalyst; Oxidative Chlorinating; Reaction; Ethylene, Mechanism; Cucl2; Fluorescence Spectroscopy; $\Gamma$-Al2O3; X-Ray; Microscopy.

\section{Introduction}

The industrial process of oxidative chlorination of ethylene (EOC) is most effective in the production of 1.2-dichloroethane (1.2DCE) and vinyl chloride monomer (VCM), because it allows achieves $99 \%$ conversion of raw materials and $98.8 \%$ selectivity to 1.2-DCE [1].

The catalysts of this process are chlorides of $\mathrm{Cu}^{+1,+2}$, which are deposited on the microspheric of aluminum oxide $-\gamma-\mathrm{Al}_{2} \mathrm{O}_{3}$ in the amount of $5-8 \%$. The catalyst of EOC should have a suitable in an industrial synthesis reactor of 1.2-DCE. EOC process is carried out in a fluidized bed of catalyst, and a stationary layer at a temperature in the reaction zone is 200 to $250^{\circ} \mathrm{C}$ and a pressure above 0.25 to $0.4 \mathrm{MPa}$ [2].

The reaction of EOC in 1.2-EDC proceeds according to Equation [3]:

$$
\begin{aligned}
& \mathrm{C}_{2} \mathrm{H}_{4}+2 \mathrm{HCl}+0,5 \mathrm{O}_{2} \rightarrow \mathrm{C}_{2} \mathrm{H}_{4} \mathrm{Cl}_{2}+\mathrm{H}_{2} \mathrm{O}+\mathrm{Q} \\
& \mathrm{C}_{2} \mathrm{H}_{4}+3 \mathrm{O}_{2} \rightarrow 2 \mathrm{CO}_{2}+2 \mathrm{H}_{2} \mathrm{O} \\
& \mathrm{C}_{2} \mathrm{H}_{4}+2 \mathrm{O}_{2} \rightarrow 2 \mathrm{CO}+2 \mathrm{H}_{2} \mathrm{O}
\end{aligned}
$$

At the same time, Side reactions may occur, the following reaction products, as a chlorine organic waste (HOW) are formed:carbon tetrachloride

$\mathrm{C}_{2} \mathrm{H}_{4}+8 \mathrm{HCl}+3 \mathrm{O}_{2} \rightarrow 2 \mathrm{CCl}_{4}+6 \mathrm{H}_{2} \mathrm{O}$

Chloral

$$
\mathrm{C}_{2} \mathrm{H}_{4}+3 \mathrm{HCl}+2 \mathrm{O}_{2} \rightarrow \mathrm{C}_{2} \mathrm{HCl}_{3} \mathrm{O}+3 \mathrm{H}_{2} \mathrm{O}
$$

1, 1, 2- threechloroethane (TCE) and other impurities, $1-2 \%$ of the obtained 1.2-DCE.

$\mathrm{C}_{2} \mathrm{H}_{4}+3 \mathrm{HCl}+\mathrm{O}_{2} \rightarrow \mathrm{C}_{2} \mathrm{H}_{3} \mathrm{Cl}_{3}+2 \mathrm{H}_{2} \mathrm{O}$

According to well-known authors [4], chlorine copper undergoes such transformations in this chemical process:

$$
\begin{aligned}
& \mathrm{C}_{2} \mathrm{H}_{4}+2 \mathrm{CuCl}_{2} \rightarrow \mathrm{C}_{2} \mathrm{H}_{4} \mathrm{Cl}_{2}+\mathrm{Cu}_{2} \mathrm{Cl}_{2} \\
& \mathrm{Cu}_{2} \mathrm{Cl}_{2}+0,5 \mathrm{O}_{2}+2 \mathrm{HCl} \rightarrow 2 \mathrm{CuCl}_{2}+\mathrm{H}_{2} \mathrm{O}
\end{aligned}
$$

However, the influence of the carrier $\gamma-\mathrm{Al}_{2} \mathrm{O}_{3}$ has not been studied. Although the same authors argue that chloride copper without the carrier $\gamma-\mathrm{Al}_{2} \mathrm{O}_{3}$ does not catalyze the reaction of EOC to 1.2DCE [5]. Namely two types of catalysts were considered - deposited catalyst X1 of the firm «Harshow», with copper chlorides supported onto an alumina surface, and permeated MEDC-B catalyst located in the internal pores of the support of the firm «SudChemie Catalyst». $\mathrm{CuCl}_{2}$ interactions with $\gamma-\mathrm{Al}_{2} \mathrm{O}_{3}$ surface groups (三Al-OH) lead to complex compounds formation with $\left[\mathrm{CuCl}_{4}\right]^{-2}$ and $\left[\mathrm{CuCl}_{2}\right]^{-1}$. A new mechanism of metal-complex catalysis of the EOC into 1.2--DCE with $\mathrm{Al}_{2} \mathrm{O}_{3}\left[\mathrm{CuCl}_{4}\right]_{-}{ }^{2}$ and $\mathrm{Al}_{2} \mathrm{O}_{3}\left[\mathrm{CuCl}_{2}\right]^{-1}$ surface metal complexes reacting with ethylene, hydrogen chloride, and oxygen was proposed the authors of the article in previous publications [6]. For a catalyst X1, the mechanism of formation of surface structures during its production is as follow:

$$
\begin{aligned}
& \mathrm{CuCl}_{2}+2 \mathrm{HCl} \rightarrow \mathrm{H}_{2}\left[\mathrm{CuCl}_{4}\right] \\
& \mathrm{Cu}_{2} \mathrm{Cl}_{2}+2 \mathrm{HCl} \rightarrow 2 \mathrm{H}\left[\mathrm{CuCl}_{2}\right]
\end{aligned}
$$

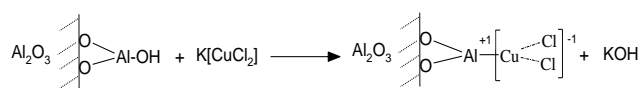




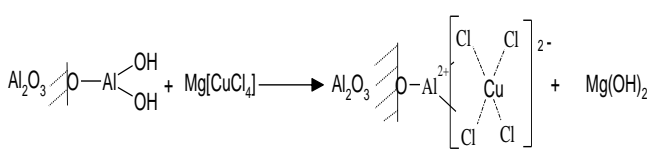

The formation of copper aluminates on the carrier $\gamma-\mathrm{Al}_{2} \mathrm{O}_{3}$ surface is also confirmed by other authors [7], [8], [9]. The structure of the surface layer of the catalyst MEDC-B can be described the quasicrystal chemistry formulas. In a spinel structure, cationic vacancies occur in the tetrahedral (A) and octahedral (B) sublattices:

$$
\begin{gathered}
(1-\alpha) C u_{A}^{\times}\left[C u_{2}^{\prime}\right]_{B}\left(C l_{4}^{\cdot}\right)_{O}\left(C l_{2}^{\prime}\right)_{i}+2 \alpha O_{2}(2 a 3)+\alpha V_{A}^{\prime \prime}\left[V_{2}^{\prime \prime \prime}\right]_{B}\left(V_{4}^{* *}\right)_{O} \rightarrow \\
\rightarrow\left(C u_{1-\alpha}^{\times} V_{\alpha}^{\prime \prime}\right)_{A}\left[C u_{2-2 \alpha}^{\prime} V_{2 \alpha}^{\prime \prime \prime}\right]_{B}\left(O_{4 \alpha}^{\times} C l_{4-4 \alpha}^{\cdot}\right)_{O}\left(C l_{2-2 \alpha}^{\prime}\right)_{i}+8 \alpha h^{\cdot}
\end{gathered}
$$

The adsorbed hydrogen reacts with the oxygen in the crystalline lattice of the spinel formation molecules $\mathrm{H}_{2} \mathrm{O}$ :

$$
\begin{aligned}
& V_{O}^{\times} \leftrightarrow V_{O}^{\bullet \bullet}+2 e^{\prime} \\
& 2 \mathrm{HCl}+\mathrm{O}_{O}^{\times} \rightarrow \mathrm{H}_{2} \mathrm{O}+2 \mathrm{Cl}^{\times}+V_{0}^{\times}
\end{aligned}
$$

Chlorine atoms react with molecules adsorbed ethylene by their adherence to the double bond with the formation of 1.2-EDC [10].

$$
4 \alpha \mathrm{Cl}_{i}^{\times}+2 \mathrm{C}_{2} \mathrm{H}_{4} \rightarrow 2 \alpha \mathrm{C}_{2} \mathrm{H}_{4} \mathrm{Cl}_{2}
$$

\section{Experimental}

\subsection{Substances}

1) $\gamma-\mathrm{Al}_{2} \mathrm{O}_{3}$ - catalyst carrier, firm 'Harshow' (USA) $\mathrm{S}_{\mathrm{sp}}=140 \mathrm{~m}^{2}$ $\mathrm{g}^{-1} ; \mathrm{V}_{\mathrm{n}},=0.4 \mathrm{~cm}^{3} \mathrm{~g}^{-1}$.

2) X1 Harshow- the commercial catalyst firm 'Harshow' (USA) $\mathrm{CuCl}_{2}$, applied from muriatic water solution on the $\gamma-\mathrm{Al}_{2} \mathrm{O}_{3}$ surface, in an amount of 5 wt. $\%$ by $\mathrm{Cu}^{+2,+1}, \mathrm{~S}_{\mathrm{sp}}=120 \mathrm{~m}^{2}$ $\mathrm{g}^{-1} ; \mathrm{V}_{\text {п }}=0.3 \mathrm{~cm}^{3} \mathrm{~g}^{-1}$.

3)MEDC-B- the commercial catalyst firm 'Sud-Chemie Catalysts' (Germany) - based $\gamma-\mathrm{Al}_{2} \mathrm{O}_{3} / \mathrm{CuCl}_{2}$ containing of 5 wt. $\%$ by $\mathrm{Cu}^{+2,+1}$, OXYMAX-B (MEDC-B) $\mathrm{S}_{\mathrm{sp}}=140 \mathrm{~m}^{2} \mathrm{~g}^{-1}$; $\mathrm{V}_{\text {п }}=0.36 \mathrm{~cm}^{3} \mathrm{~g}^{-1}$.

4) $\mathrm{CuCl}_{2} \cdot 2 \mathrm{H}_{2} \mathrm{O}$ - the main component derived from EOC catalysts.

5) $\mathrm{H}_{2} \mathrm{CuCl}_{2}$ and. $\mathrm{H}_{2} \mathrm{CuCl}_{4}$ - hydrochloride of the main component derived from EOC catalysts.

\subsection{Methods}

Method for measuring energy dispersion X-ray with the aid of fluorescence spectroscopy (EDX-7000 "Simatsu" elements: Na-U) was used to obtain the results of the structure analysis $\mathrm{CuCl}_{2}$, $\mathrm{H}_{2} \mathrm{CuCl}_{4}$, and two different types oxidative chlorination of ethylene (EOC) catalysts: deposited catalyst $\mathrm{X} 1$ «Harshow» and permeated MEDC-B catalyst of the firm «Sud-Chemie Catalysts». Method of thermoelectric e-raster microscopy (VEGA 3 NT SCAN) was used for research of samples of active phases of $\mathrm{CuCl}_{2}$ and $\mathrm{H}_{2} \mathrm{CuCl}_{4}$, catalysts (EOC) of the MEDC-B and $\mathrm{X} 1$ Harshow brands. Photos were obtained at an increase of 200 to 25000 times.

\section{Results and discussion}

\subsection{Measuring energy dispersion $x$-ray with the aid of fluorescence spectroscopy}

The figures below show the EDX spectra of the dispersive $\mathrm{x}$-ray fluorescence spectrometer of the active phase $\mathrm{CuCl}_{2}$ on the surface of catalyst for the EOC, with interpretation of the mass content of the elements: Figure 1.1 and 1.2, table 1
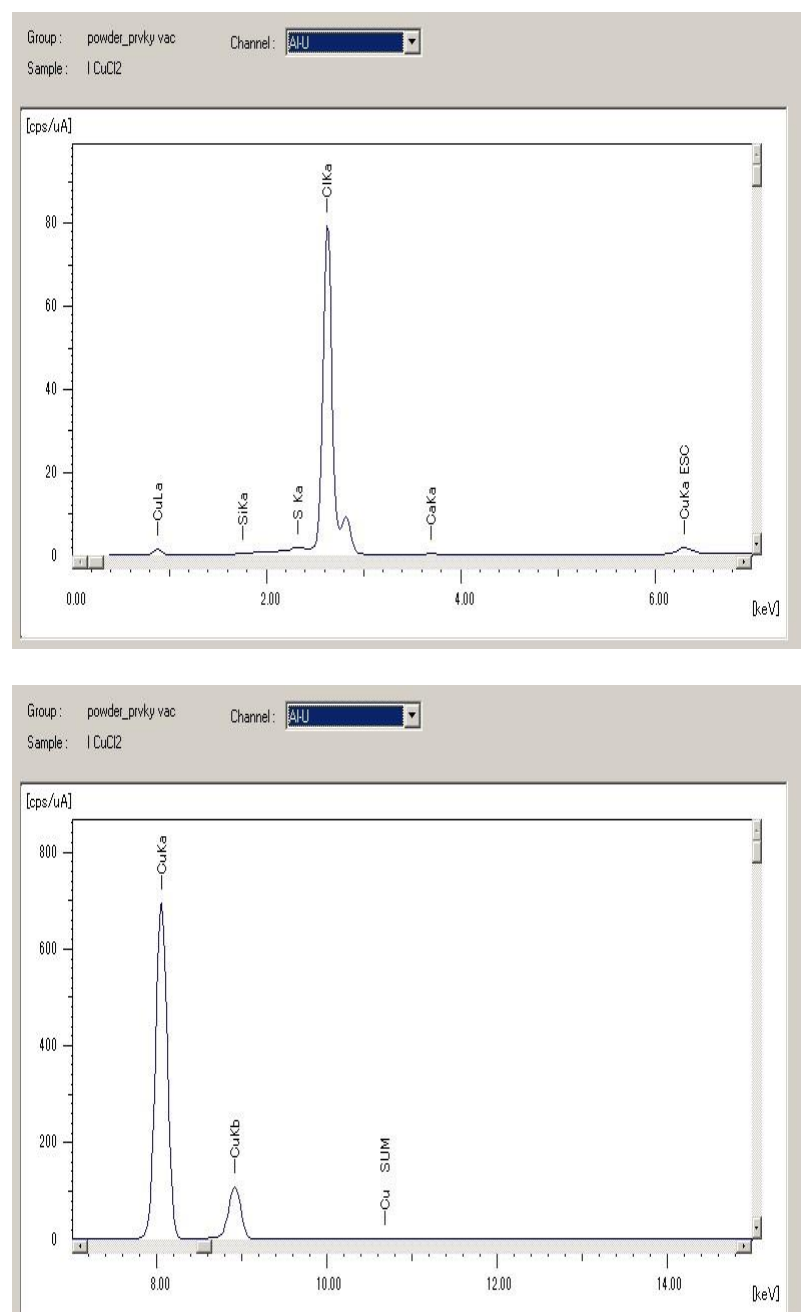

Fig. 1.1 and 1.2: EDX Spectra of the Dispersive X-Ray Fluorescence Spectrometer of the Active Phase of Cucl2 on the Surface of the Catalyst of the Process of EOC for the Mass Content of the Elements.

Table 1: Interpretation Fig.1.1,1.2 for the Mass Content of Elements in $\mathrm{Cucl}_{2}$

№Analyte $\left(\mathrm{CuCl}_{2}\right)$ Result [3-sigma] Proc.-Calc. Line Int $(\mathrm{cps} / \mathrm{uA})$

1) $\mathrm{Cu} 54.302 \%$ [ 0.077] Quan-FP CuKa 5667.375

2) $\mathrm{Cl} 43.804 \%$ [ 0.104] Quan-FP ClKa 213.5789

3) Si $1.360 \%$ [0.134] Quan-FP SiKa 2.5428

4) S $0.361 \%[0.014]$ Quan-FP S Ka 2.2219

The figures below show EDX spectra of the dispersive x-ray fluorescence spectrometer of the active phase $\mathrm{CuCl}_{2}$ on the surface of the catalyst for the EOC, Figure 2.1 and 2.2 with interpretation them on the mass content of oxides elements (table 2).

Table 2: Interpretation Figure 2.1,2.2 for the Mass Content of Oxides Elements in $\mathrm{Cucl}_{2}$

№Analyte $\left(\mathrm{CuCl}_{2}\right)$ Result [3-sigma] Proc.-Calc. Line Int.(cps/uA)

1) $\mathrm{CuO} 57.342 \%$ [0.081] Quan-FP CuKa 5681.1821

2) $\mathrm{Cl} 39.180 \%$ [ 0.093] Quan-FP ClKa 219.9832

3) $\mathrm{P}_{2} \mathrm{O}_{5} 2.170 \%[0.077]$ Quan-FP P Ka 5.0855

4) $\mathrm{SO}_{3} 0.716 \%[0.029]$ Quan-FP S Ka 2.0191

5) $\mathrm{SiO}_{2} 0.373 \%[0.071]$ Quan-FP SiKa 0.2239

6) $\mathrm{CaO} 0.219 \%[0.012]$ Quan-FP CaKa 0.7954 

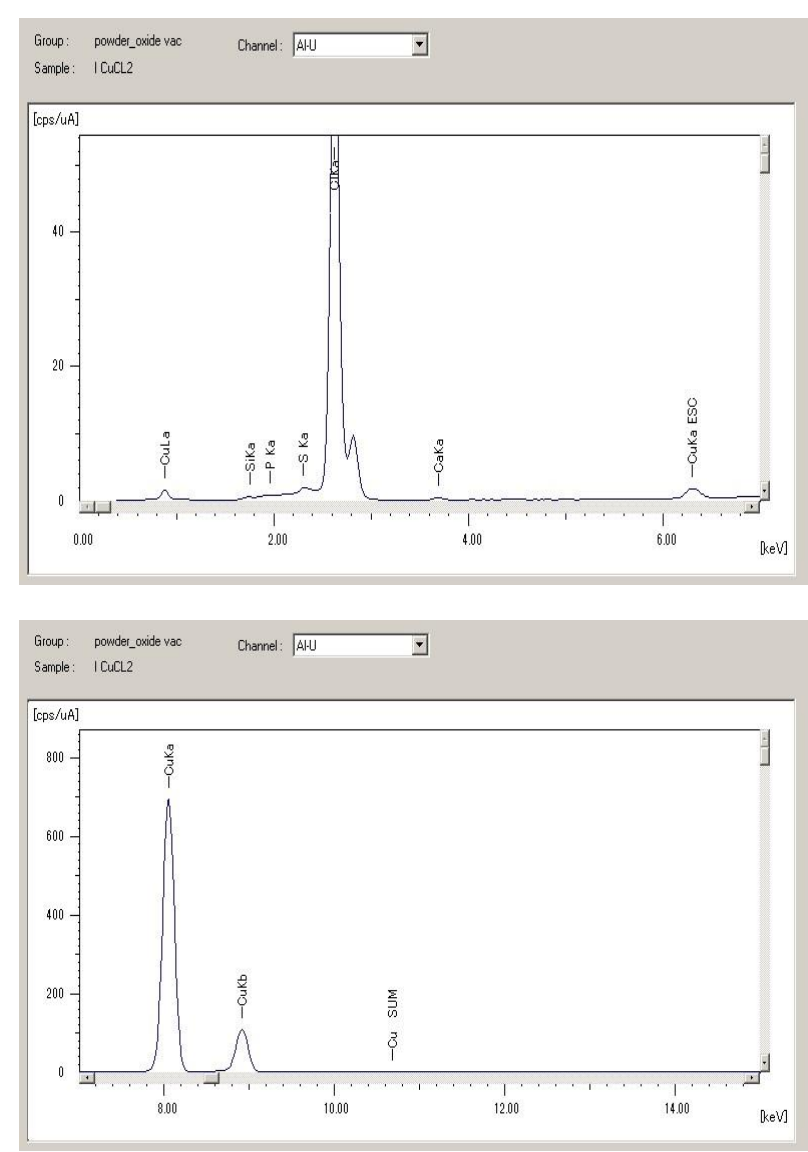

Fig. 2.1 and 2.2: EDX Spectra of the Dispersive X-Ray Fluorescence Spectrometer of the Active Phase of Cucl2 on the Surface of the Catalyst of the Process of EOC for the Mass Content of the Oxides Elements.

As we can see from the comparison of two spectra in the active phase of $\mathrm{CuCl}_{2}$ on the surface of the industrial catalyst of the process of EOC in addition to the main elements of cuprum and chlorine (96.5\%) (Fig. 1.1 and 1.2), there are also phosphorus sulfur, silicon and calcium. These elements in terms of oxides are observed in Fig. 2.1. and 2.2. Moreover, in the composition of oxides appears sixth phosphorus oxide (number $3-\mathrm{P}_{2} \mathrm{O}_{5}$ ), which is not in the elemental composition.

The figures below show EDX spectra of the dispersive x-ray fluorescence spectrometer of the active phase $\mathrm{H}_{2} \mathrm{CuCl}_{4}$ on the surface, the catalyst for the EOC, Figure 3.1. and 3.2 with interpretation on the mass content of the elements (table 3).

Table 3: Interpretation Figure 3.1, 3. 2 for the Mass Content of Elements in $\mathrm{H}_{2} \mathrm{Cucl}_{4}$

№ Analyte Result [3-sigma] Proc.-Calc. Line Int. (cps/uA) $\mathrm{H}_{2} \mathrm{CuCl}_{4}$

1) $\mathrm{Cu} 50.407 \%$ [0.070] Quan-FP CuKa 5959.8219

2) $\mathrm{Cl} 47.471 \%$ [0.108] Quan-FP ClKa 263.0354

3) Si $1.279 \%[0.117]$ Quan-FP SiKa 2.8232

4) S $0.806 \%$ [0.019] Quan-FP S Ka 10.4985

5) $\quad \mathrm{Ni} 0.037 \%$ [ 0.005] Quan-FP NiKa 4.2460
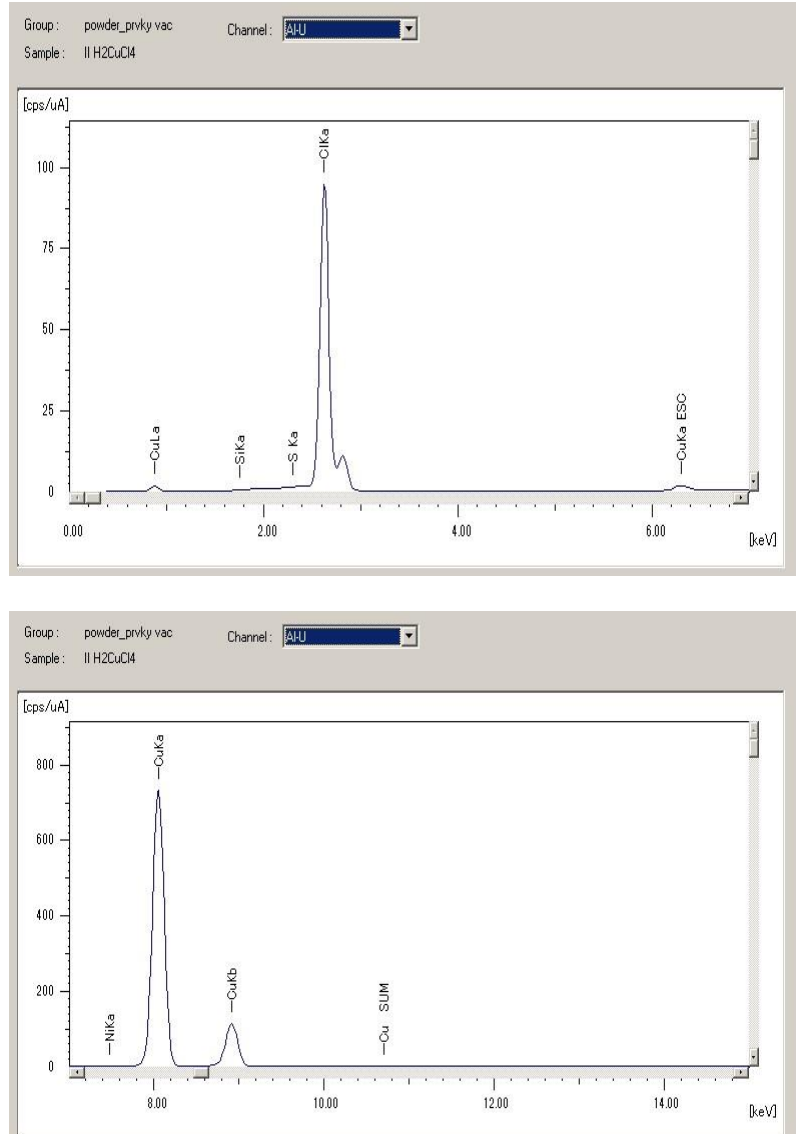

Fig. 3.1 and 3.2: EDX Spectra of A Dispersive X-Ray Fluorescence Spectrometer of the Active Phase Of H2cucl4 on the Surface of the Catalyst of the Process of EOC, for the Mass Content of the Elements.

The figures below show the EDX spectra of the dispersive $\mathrm{x}$-ray fluorescence spectrometer of the active phase $\mathrm{H} 2 \mathrm{CuCl} 4$ on the surface, the catalyst for EOC, Fig. 4.1 and 4.2 with interpretation them on the mass content of oxide elements (table 4).

Table 4: Interpretation Figure 4.1,4.2 for the Mass Content of Oxides Elements in $\mathrm{H}_{2} \mathrm{Cucl}_{4}$

\begin{tabular}{l} 
№Analyte Result [3-sigma] Proc.-Calc. Line Int. (cps/uA) \\
$\mathrm{H}_{2} \mathrm{CuCl}_{4}$ \\
\hline 1) $\mathrm{CuO} 55.242 \%$ [ 0.076] Quan-FP CuKa 5998.5582 \\
2) $2 \mathrm{Cl} 41.833 \%$ [0.095] Quan-FP ClKa 259.8103 \\
3) $\mathrm{SiO}_{2} 2.482 \%$ [0.233] Quan-FP SiKa 2.7955 \\
4) $\mathrm{P}_{2} \mathrm{O}_{5} 0.443 \%$ [0.048] Quan-FP P Ka 0.6650
\end{tabular}

As we can see from the comparison of the two spectra in the active phase of $\mathrm{H} 2 \mathrm{CuCl} 4$ from the surface of the industrial catalyst of EOC in addition to the basic elements of cuprum and chlorine (97.85\%) (Fig. 3.1 and 3.2), phosphorus, sulfur, silicon and nickel, as well as silicon and phosphorus oxides (Fig. 4.1 and 4.2). Moreover, instead of nickel and sulfur, the fourth phosphorus oxide (№ $4-\mathrm{P}_{2} \mathrm{O}_{5}$ ) appears, which is not present in the elemental composition.

The figures below show EDX spectra of the dispersive x-ray fluorescence spectrometer of the active phase $\mathrm{H} 2 \mathrm{CuCl} 2$ on the surface, the catalyst for EOC, Figure 5.1. In addition, 5.2 with interpretation of mass content of elements and their oxides (table 5). 

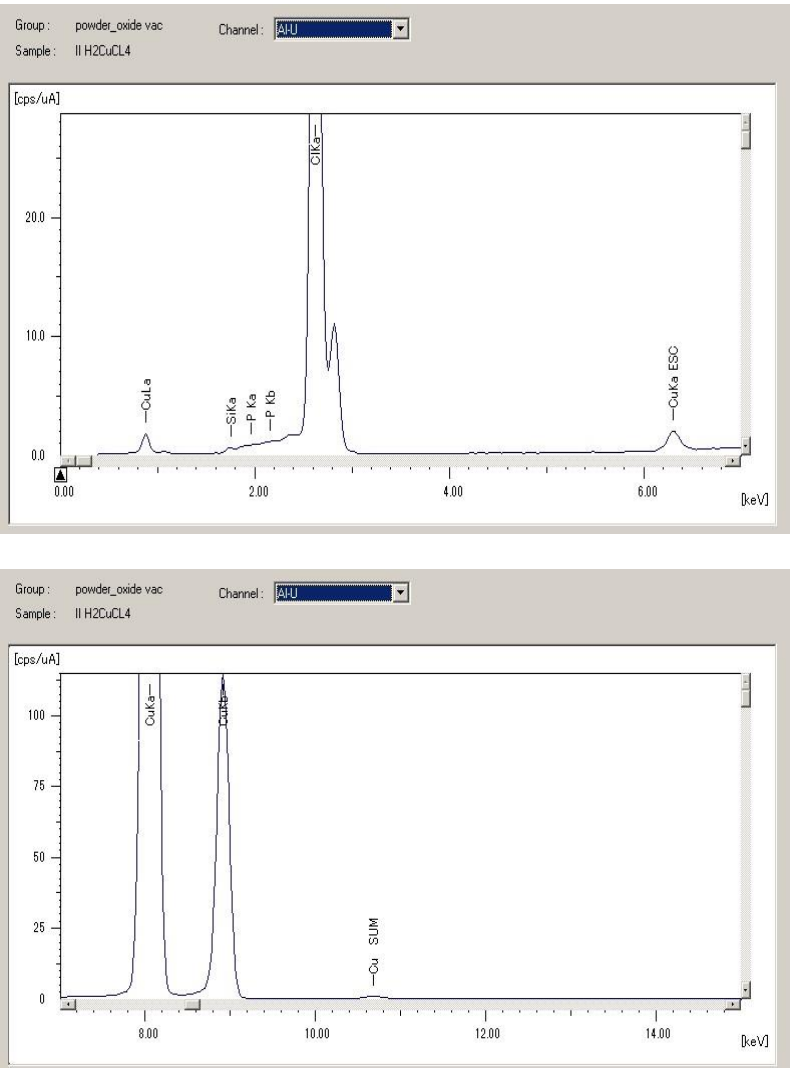

Fig. 4.1 and 4.2: EDX Spectra of a Dispersive X-Ray Fluorescence Spectrometer of the Active Phase of $\mathrm{H}_{2}$ cucl4. On the Surface of the Catalyst of EOC, for the Mass Content of the Oxides Elements.

Table 5: Interpretation Figure 5.1,5.2 for the Mass Content of on Elements and Their Oxides in $\mathrm{H}_{2} \mathrm{Cucl}_{2}$

\begin{tabular}{|l|l|}
\hline $\begin{array}{l}\text { № Analyte } \mathrm{H}_{2} \mathrm{CuCl}_{2} \text { Result [3-sigma] Proc.-Calc.Line Int. } \\
\text { (cps/uA) }\end{array}$ \\
\hline 1) & $\mathrm{Cu} \mathrm{56.643 \%} \mathrm{\%} \mathrm{0.080]} \mathrm{Quan-FP} \mathrm{CuKa} \mathrm{5685.8160}$ \\
2) & $\mathrm{Cl} 42.452 \%$ [ 0.105] Quan-FP ClKa 199.2339 \\
3) & $\mathrm{P} 0.707 \%$ [ 0.069] Quan-FP P Ka 3.1224 \\
4) & $\mathrm{Si} 0.199 \%$ [ 0.037] Quan-FP SiKa 0.2103 \\
\hline
\end{tabular}

№ Analyte Result [3-sigma] Proc.-Calc. Line Int.(cps/uA) $\mathrm{H}_{2} \mathrm{CuCl}_{2}$

1) $\mathrm{CuO} 61.503 \%$ [0.087] Quan-FP CuKa 5689.116

2) $\mathrm{Cl} 38.080 \%$ [ 0.093] Quan-FP ClKa 201.478

3) $\mathrm{SiO}_{2} 0.417 \%[0.073]$ Quan-FP SiKa 0.2278

As can be seen from the comparison of the two spectra in the active phase of $\mathrm{H}_{2} \mathrm{CuCl}_{2}$ on the surface of the industrial catalyst of the process of EOC in addition to the basic elements of cuprum and chlorine (99\%) (Fig. 5.1 and 5.2), there are also smaller amounts of phosphorus, silicon, as well as silicon oxides.

The figures below show the EDX spectra of the dispersive $\mathrm{x}$-ray fluorescence spectrometer of the applied form of the industrial catalyst of the process EOC type X1 with their decoding of the mass content of the elements (Fig. 6.1, 6.2), as well as X1 decoding them by mass content of oxide elements (Fig. 7.1, 7.2, 7.3) (table 6.7)
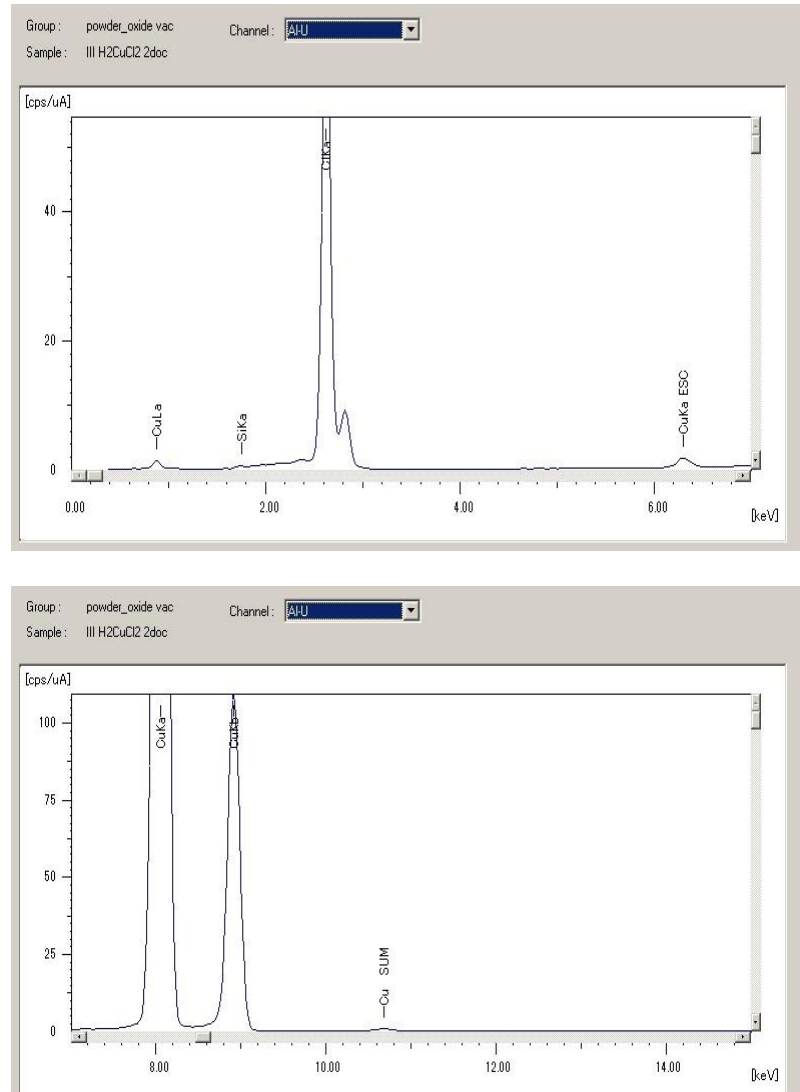

Fig. 5.1 and 5.2: EDX Spectra of a Dispersive X-Ray Fluorescence Spectrometer of the Active Phase of $\mathrm{H} 2 \mathrm{cucl} 2$ on Elements and Their Oxides in the Surface of the Catalyst pf EOC.
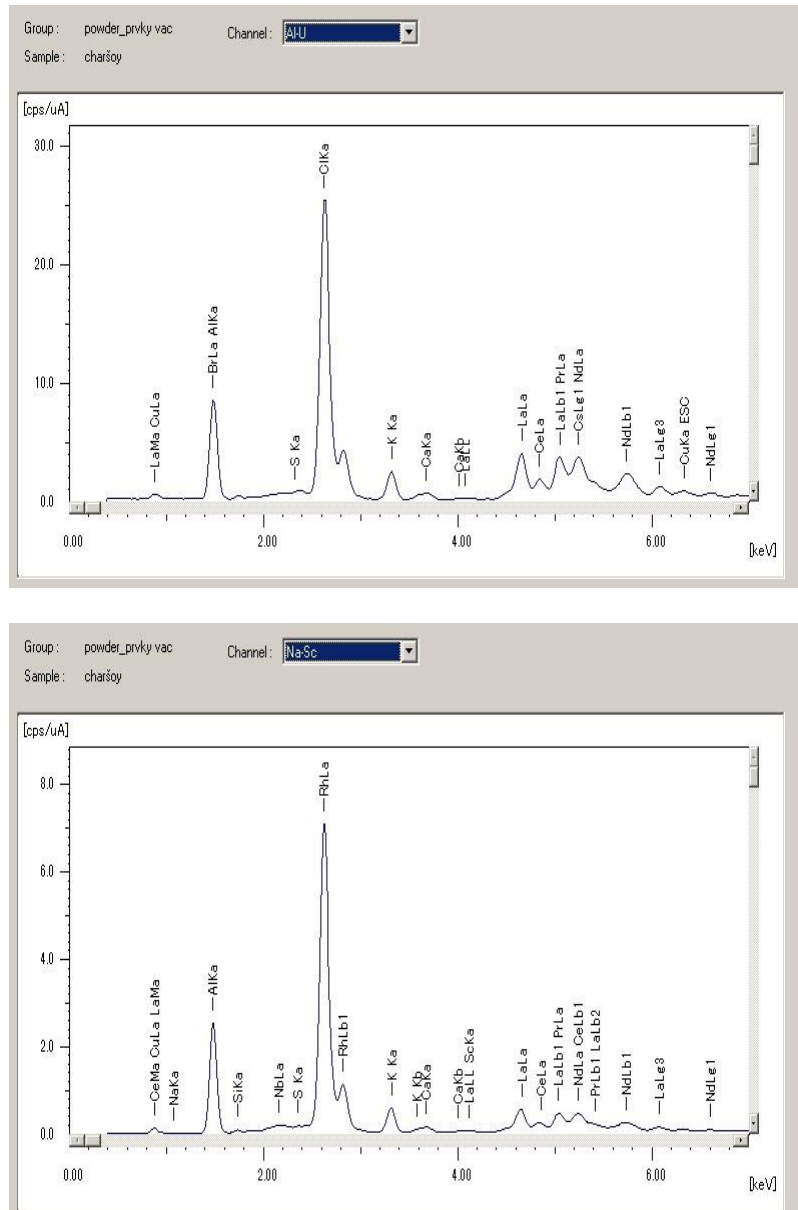

Fig. 6.1 and 6.2: EDX Spectra of the Dispersive X-Ray Fluorescence Spectrometer of the Applied Form of the Industrial Catalyst of the Process EOC Type X1 Harshow for the Mass Content of the Elements. 
Table 6: Interpretation Figure 6.1, 6. 2 for the Mass Content of Elements in the Industrial Catalyst of the Process EOC Type X1 Harshow

\section{№ Analyte Result [3-sigma] Proc.-Calc. Line Int.(cps/uA)} X1 Harshow
1) $\mathrm{Al} 56.928 \%$ [0.276] Quan-FP AlKa 22.1342
2) $\mathrm{Cl} 21.583 \%$ [ 0.106] Quan-FP ClKa 149.1051
3) $\mathrm{Cu} 11.286 \%$ [0.020] Quan-FP CuKa 1174.1582
4) $\mathrm{La} 2.991 \%$ [0.032] Quan-FP LaLa 25.6763
5) K 2.181\% [0.019] Quan-FP K Ka 6.1013
6) $\mathrm{Nd} 1.987 \%$ [0.018] Quan-FP NdLa 25.4699
7) $\mathrm{Ce} 0.896 \%$ [0.013] Quan-FP CeLa 8.8614
8) Pr $0.880 \%$ [0.010] Quan-FP PrLa 9.9532
9) $\mathrm{Si} 0.538 \%$ [0.033] Quan-FP SiKa 0.3898
10) $\mathrm{Ca} 0.310 \%$ [ 0.010] Quan-FP CaKa 1.2508
11) $\mathrm{S} 0.232 \%$ [ 0.012] Quan-FP S Ka 0.9563
12) $\mathrm{Br} 0.157 \%$ [ 0.002] Quan-FP BrKa 24.6734
13) Sc $0.021 \%$ [ 0.005] Quan-FP ScKa 0.1411
14) Sr $0.008 \%$ [ 0.001] Quan-FP SrKa 1.5020

As we can see from the comparison of the two spectra in the industrial catalyst of the process of EOC type X1Harshow in addition to the basic elements of aluminum, cuprum and chlorine and their oxides (91-93\%) (Figs. 6 and 7), are present also other rareearth elements and their oxides: lanthanum, niobium, cerium, praseodymium, scandium, strontium, bromine, as well as silicon oxides, potassium, calcium, sulfur.

Table 7: Interpretation Figure 7.1, 7.2, 7.3 for the Mass Content of Oxides Elements in the Industrial Catalyst of the Process EOC Type X1 Harshow.

№ Analyte Result [3-sigma] Proc.-Calc. Line Int.(cps/uA) X1Harshow

1) $\mathrm{Al}_{2} \mathrm{O}_{3} 73.646 \%[0.359]$ Quan-FP AlKa 21.9293

2) $\mathrm{Cl} 12.442 \%$ [0.063] Quan-FP ClKa 148.6249

3) $\mathrm{CuO} 6.943 \%$ [0.013] Quan-FP CuKa 1185.6558

4) $\mathrm{La}_{2} \mathrm{O}_{3} 1.907 \%$ [0.021] Quan-FP LaLa 26.2509

5) $\mathrm{K}_{2} \mathrm{O} 1.457 \%$ [0.013] Quan-FP K Ka 6.2402

6) $\mathrm{Nd}_{2} \mathrm{O}_{3} 1.148 \%[0.011]$ Quan-FP NdLa 23.8294

7) $\mathrm{CeO}_{2} 0.608 \%$ [0.009] Quan-FP CeLa 9.2243

8) $\mathrm{Pr}_{6} \mathrm{O}_{11} 0.546 \%$ [0.021] Quan-FP PrLa 9.6449

9) $\mathrm{SiO}_{2} 0.529 \%[0.042]$ Quan-FP SiKa 0.3003

10) $\mathrm{SO}_{3} 0.438 \%$ [ 0.018] Quan-FP S Ka 1.2226

11) $\mathrm{CaO} 0.236 \%$ [ 0.007] Quan-FP CaKa 1.2723

12) $\mathrm{Br} 0.073 \%$ [ 0.001] Quan-FP BrKa 25.0776

13) $\mathrm{Sc}_{2} \mathrm{O}_{3} 0.018 \%$ [0.004] Quan-FP ScKa 0.1451

14) $\mathrm{SrO} 0.004 \%$ [ 0.001] Quan-FP SrKa 1.5736

15) $\mathrm{Y}_{2} \mathrm{O}_{3} 0.003 \%$ [0.001] Quan-FP Y Ka 1.0728

16) $\mathrm{Rb}_{2} \mathrm{O} 0.002 \%$ [ 0.001] Quan-FP RbKa 0.8539

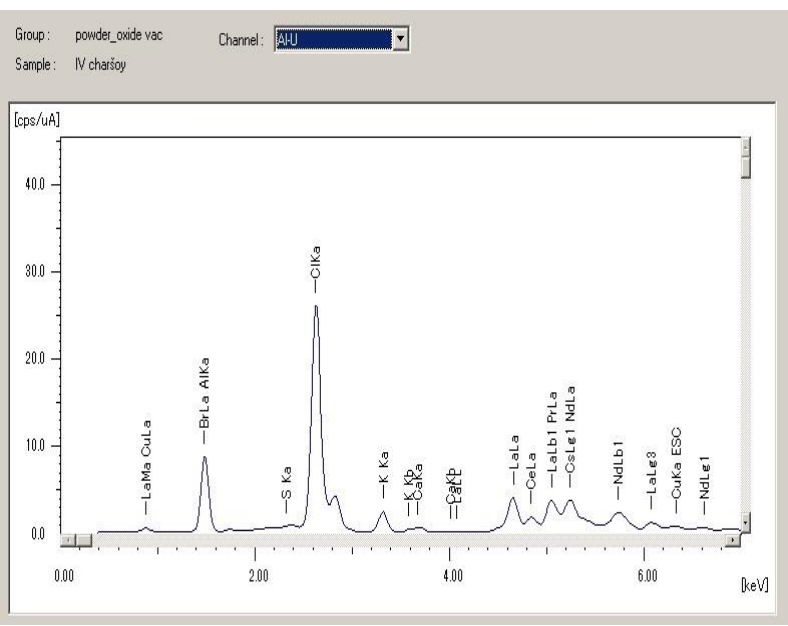

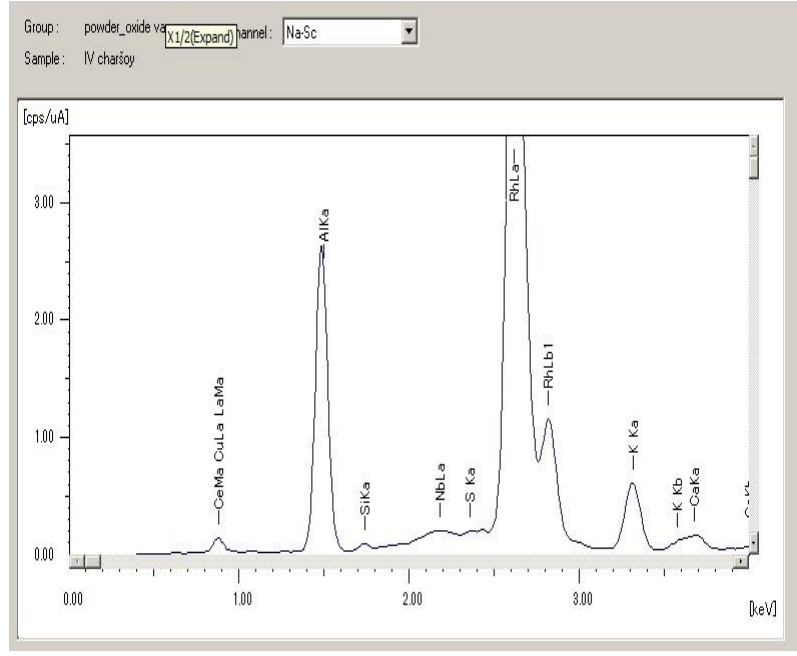

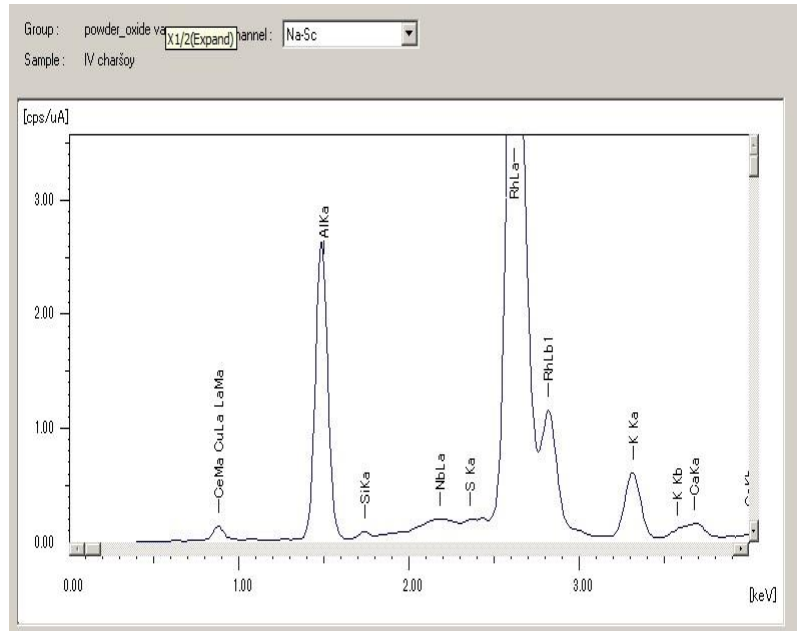

Fig. 7.1, 7.2, and 7.3: EDX Spectra of the Dispersive X-Ray Fluorescence Spectrometer of the Applied Form of the Industrial Catalyst of the Process EOC Type Xone Harshow for the Mass Content of Oxide Elements.

Moreover, in the oxide composition of the catalyst, there are traces of strontium, yttrium and rubidium, and the total content of copper chlorides in the oxide composition of catalyst X1 Harshow, which is closest to the copper content, advanced in the requirements for an industrial catalyst, does not exceed 6-13\%.

The presence of the catalyst X1 Harshow, the impurities of lanthanum-La, potassium-K and niobium-Nd $(\Sigma=5 \%)$ and their oxides $(\Sigma=9 \%)$ (Fig. 7.1.7.2.7.3) proves their role as promoters EOC reaction [11-12]. They react in the form of corresponding salts of cuprum with the dustable hydroxyl groups of the carrier $\gamma-\mathrm{Al}_{2} \mathrm{O}_{3}$ by reactions (№. 9 and 10 ), thus forming complex compounds on the surface, which subsequently catalyze the reaction of OCE in 1.2-DCE as shown earlier by [6]. At the same time, relatively large amounts of $\mathrm{K}$ and La do not positively influence the work of the catalyst X1 Harshow [13-14]. 

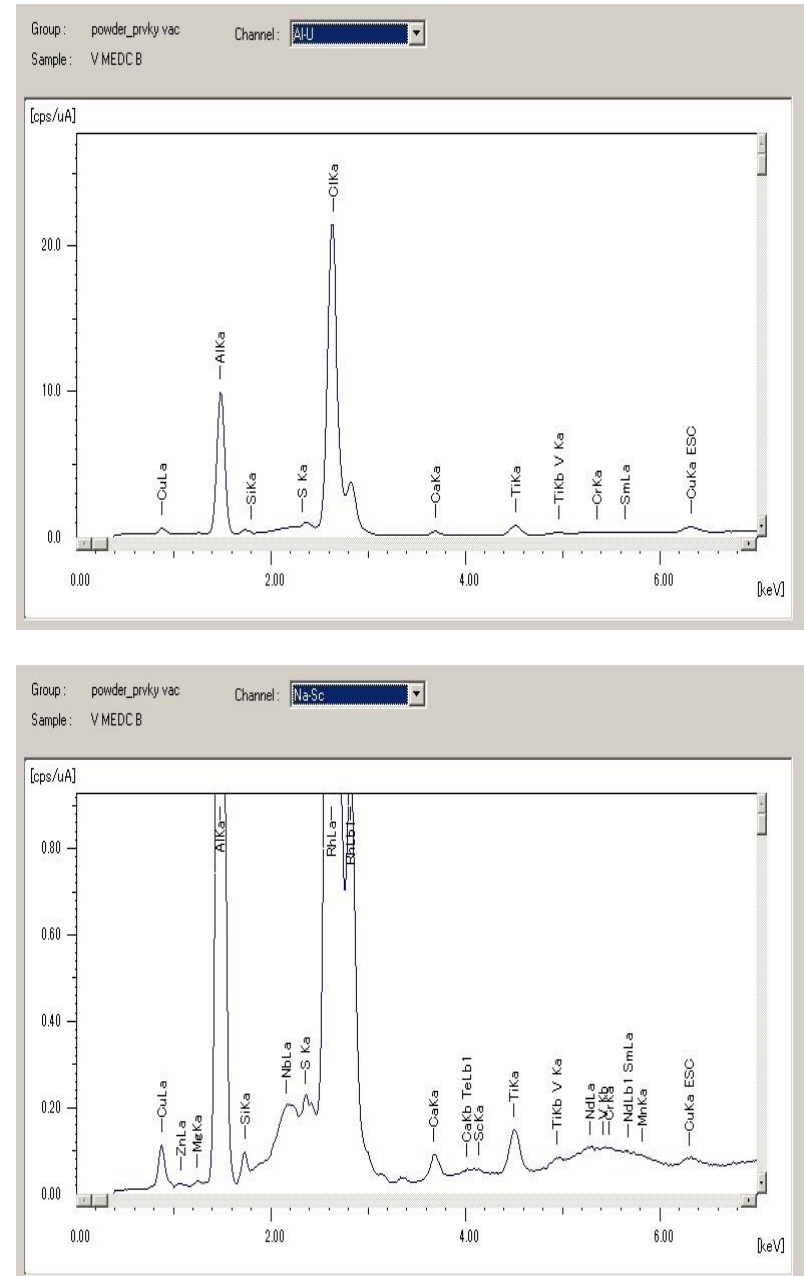

Fig. 8.1, 8.2: EDX Spectra of a Dispersive X-Ray Fluorescence Spectrometer of the Applied Form of the Industrial Catalyst of the EOC Process of the MEDC-B Type for Mass Content of the Elements.

Table 8:. Interpretation Figure 8.1, 8.2 for the Mass Content of Elements in the Industrial Catalyst of the Process EOC Type MEDC-B

№Analyte Result [3-sigma] Proc.-Calc. Line Int. (cps/uA) MEDC-B
1) $\mathrm{Al} 64.353 \%$ [0.286] Quan-FP AlKa 24.8383
2) $\mathrm{Cl} 21.092 \%$ [ 0.116] Quan-FP ClKa 125.5905
3) $\mathrm{Cu} 12.116 \%[0.020]$ Quan-FP CuKa 1448.9077
4) $\mathrm{Mg} 1.241 \%[0.249]$ Quan-FP MgKa 0.0712
5) Si $0.564 \%$ [0.038] Quan-FP SiKa 0.3498
6) S $0.466 \%$ [0.014] Quan-FP S Ka 1.6519
7) Ti $0.200 \%$ [0.005] Quan-FP TiKa 4.2463
8) $\mathrm{Ca} 0.195 \%$ [0.008] Quan-FP CaKa 0.7174
9) $\mathrm{Sm} 0.054 \%[0.010]$ Quan-FP SmLa 0.8485
10) Sc $0.029 \%$ [ 0.004] Quan-FP ScKa 0.1773
11) $\mathrm{Cr} 0.018 \%$ [ 0.003] Quan-FP CrKa 0.7645

The figures below show the EDX spectra of the dispersive $\mathrm{x}$-ray fluorescence spectrometer of the industrial catalyst of the EOC process of the impregnated type MEDC-B with their decoding of the mass content of the elements (Fig. 8.1.8.2) Table 8.

In the other figures shown below, the EDX spectra of the dispersive $\mathrm{x}$-ray fluorescence spectrometer of the industrial catalyst of the EOC process of the impregnated type MEDC-B with their decoding of the mass content of oxide elements are shown (Fig. 9.1 , 9.2) (table 9)
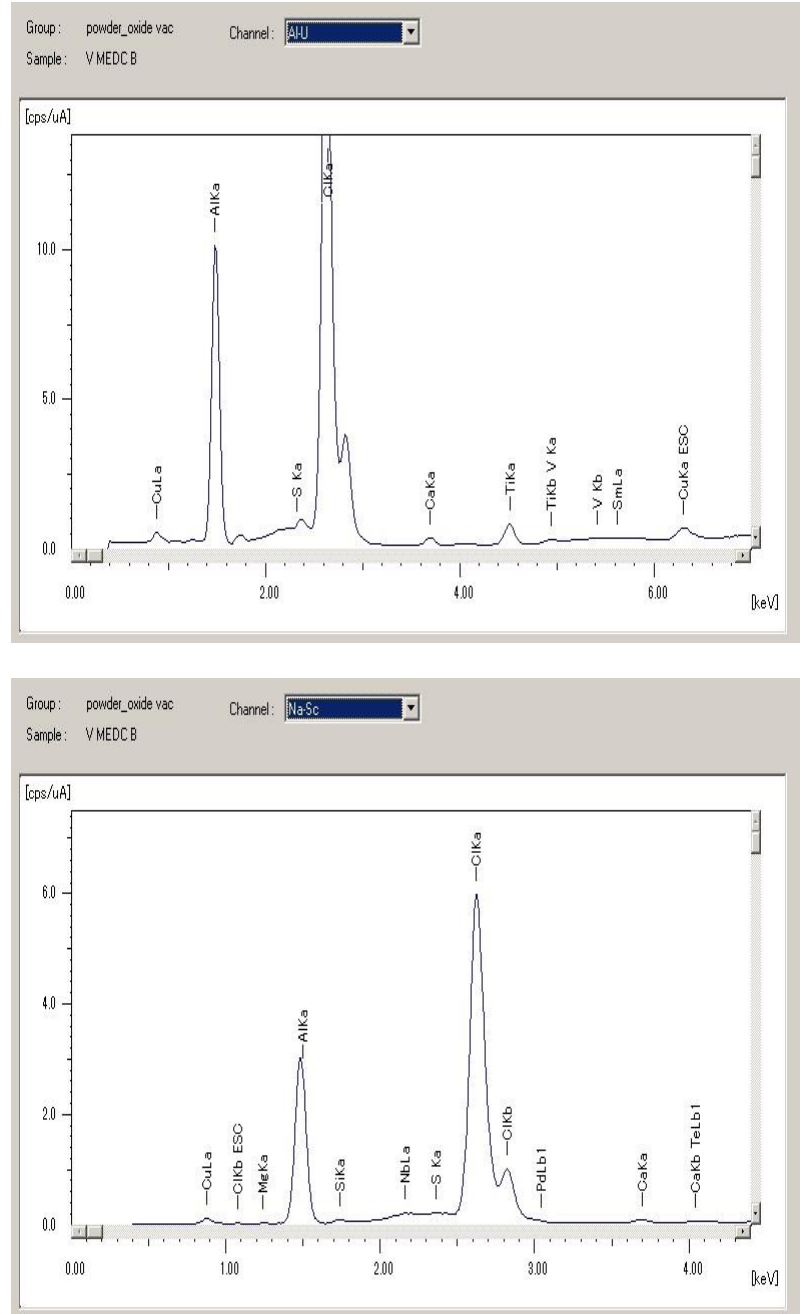

Fig. 9.1, 9.2: EDX Spectra of the Dispersive X-Ray Fluorescence Spectrometer of the Applied form of the Industrial Catalyst of the EOC Process of MEDC-B Type for the Mass Content of Oxide Elements.

Table 9:.Interpretation Figure 9.1,9.2 for the Mass Content of Oxides Elements in the Industrial Catalyst of the Process EOC Type MEDC-B

№Analyte Result [3-sigma] Proc.-Calc. Line Int. (cps/uA) MEDC-B
1) $\mathrm{Al}_{2} \mathrm{O}_{3} 80.010 \%[0.354]$ Quan-FP AlKa 25.0849
2) $\mathrm{Cl} 10.659 \%$ [0.029] Quan-FP ClKa 68.4271
3) $\mathrm{CuO} 6.534 \%$ [0.011] Quan-FP CuKa 1449.000
4) $\mathrm{MgO} 1.241 \%[0.249]$ Quan-FP MgKa 0.0712
5) $\mathrm{SiO}_{2} 0.644 \%$ [0.043] Quan-FP SiKa 0.3550
6) $\mathrm{SO}_{3} 0.577 \%[0.017]$ Quan-FP S Ka 1.5734
7) $\mathrm{TiO}_{2} 0.160 \%$ [0.004] Quan-FP TiKa 4.3976
8) $\mathrm{CaO} 0.127 \%[0.005]$ Quan-FP CaKa 0.7176
9) $\mathrm{Sm}_{2} \mathrm{O}_{3} 0.036 \%$ [0.005] Quan-FP SmLa 1.0647
10) $\mathrm{V}_{2} \mathrm{O}_{5} 0.011 \%$ [0.004] Quan-FP V Ka 0.3987

As we can see from the comparison of the two spectra (Figs. 8 and 9.) in the industrial catalyst of the process of EOC impregnated type MEDC-B in addition to the basic elements of aluminum, cuprum and chlorine and their oxides content of which (97-98\%) much larger than the catalyst $\mathrm{X} 1$, there is a significantly smaller number of other rare-earth elements and their oxides, namely only: samarium and vanadium, as well as compounds and magnesium oxide, silicon, calcium, sulfur. Moreover, in the catalyst oxide composition, the total content of copper chlorides in the oxide composition of the MEDC-B catalyst, which is slightly lower than the previous catalyst type $\mathrm{X} 1$, does not exceed $6-11 \%$ of the MEDC-B. The presence of significantly less magnesium-Mg and titanium-T ions $(\Sigma=1,1 \%)$ and their oxides $(\Sigma=2,3 \%)$ in the composition of the MEDC-B catalyst (Fig. 9.1.9.2) also demonstrates their role as promoters of the EOC reaction, but less in the role than for X1. They also react in the composition of the 
corresponding salts of cuprum with dustable hydroxyl groups of the carrier $-\gamma-\mathrm{Al}_{2} \mathrm{O}_{3}$ by reactions (№ 9 and 10 ) as well as for X1.

Figures 10 and 11 show the comparison of the content of the elements and their oxides in the active phases $\left(\mathrm{CuCl}_{2}\right.$ and $\mathrm{H}_{2} \mathrm{CuCl}_{4}$ ) of the ethylene chloride oxidation (EOC) $\mathrm{X} 1$ and MEDC-B catalysts. It is evident from the slight difference in the constituents of the main components of cuprum and chlorine, which remain consistent for both active phases.

On the Fig. 12 and 13 show the comparison of the content of the elements and their oxides in the oxidation ethylene chloride (EOC) X1 and MEDC-B catalyst. It is evident from the significant difference $(5-10 \%)$ in the constituents of the main components of aluminum oxide and of cuprum chlorides, which maintain the relevance for both types of catalyst, except for the quantity and quality of promoters that are different for these two types.

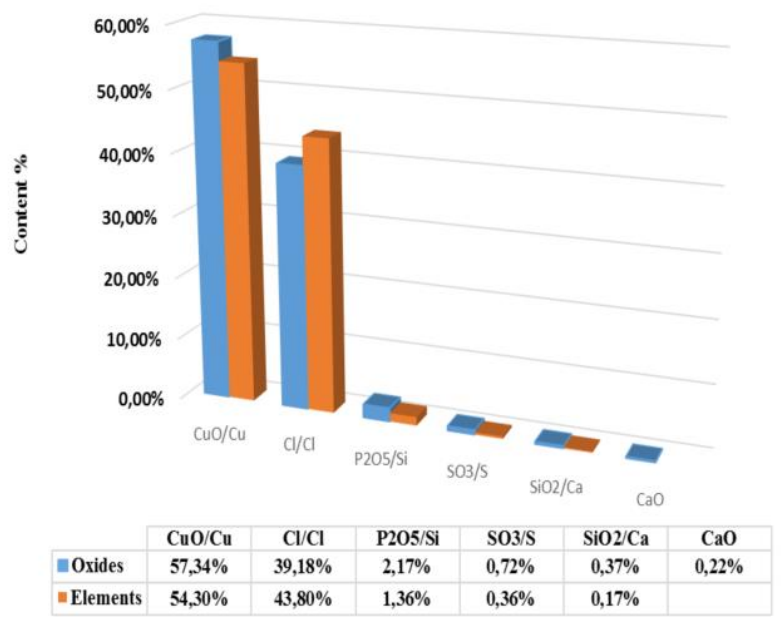

Fig. 10: Composition of the Active Phase of the Catalyst OCE $\mathrm{Cucl}_{2}$ According to the Spectra of X-Ray Fluorescence Energy Dispersion Spectroscopy EDX-7000 "Simatsu" Oxides and Elements -Na-U.

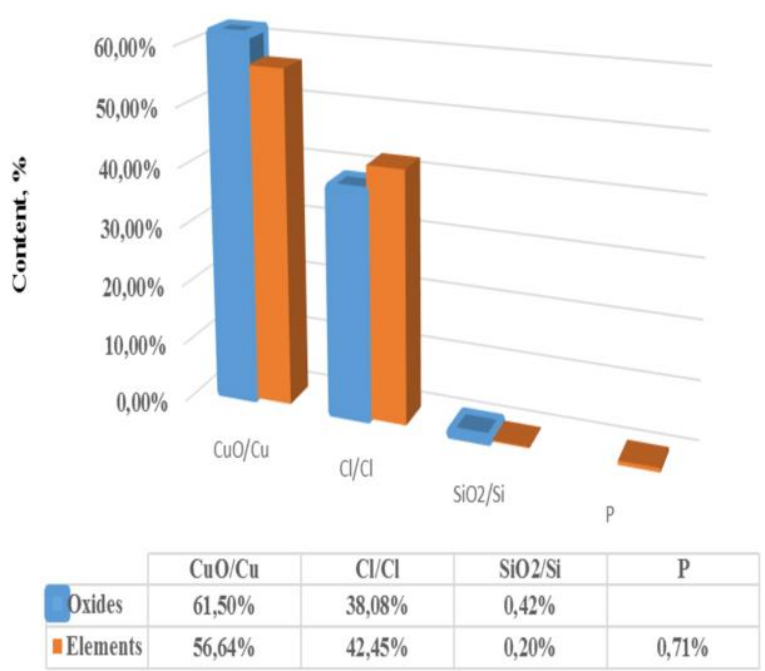

Fig.. 11: Composition of the Active Phase of the Catalyst EOC $\mathrm{H}_{2} \mathrm{Cucl}_{4}$ According to the Spectra of X-Ray Fluorescence Energy Dispersion Spectroscopy EDX-7000 "Simatsu" Oxides and Elements -Na-U.

According to information received, it is seen that $\mathrm{CuCl}_{2}$ (fig.1.2; $10 ; 11$ ) has quite large amounts of phosphorus (in terms of $\mathrm{P}_{2} \mathrm{O}_{5}-$ $2,170 \%$ ), sulphur (in terms of $\mathrm{SO}_{2}-0,716 \%$ ); minor amounts of calcium, silicon. These data show insufficiently cleaned of the copper chloride as the main raw material to obtain for the catalyst EOC. $\mathrm{CuCl}_{2}$ with adsorbed $\mathrm{HCl}$ has of admixtures of phosphorus (in terms of $\mathrm{P}_{2} \mathrm{O}_{5}-0,443 \%$ ) and silicon (in terms of $\mathrm{SiO}_{2}-$ $2,482 \%)$.

Therefore, when introducing $\mathrm{HCl}$ to the copper chloride from the solution the admixtures of phosphorus are significantly washed out, although the silicon content increases at the expense of insuf- ficiently cleaned $\mathrm{HCl}$. X1(fig.6,7,12,13) catalyst has of minor amounts of admixtures of calcium, cesium, bromine, scandium, strontium, yttrium, rubidium and quite large amounts of lanthanum (in terms of $\mathrm{La}_{2} \mathrm{O}_{3}-1,907 \%$ ), kalium (in terms of $\mathrm{K}_{2} \mathrm{O}-$ $1,457 \%$ ), neodymium (in terms of $\mathrm{Nd}_{2} \mathrm{O}_{3}-1,148 \%$ ); a little less number of cerium (in terms of $\mathrm{CeO}_{2}-0,608 \%$ ), praseodymium (in terms of Pr6O11 - 0,546\%), silicon (in terms of $\mathrm{SiO}_{2}-$ $0,529 \%$ ), sulphur (in terms of $\mathrm{SO}_{2}-0,438 \%$ ).

As for the MEDC-B (fig.8, 9, 12, 13) catalyst it has of minor amounts of admixtures calcium, vanadium, samarium, titanium, and quite large amounts of magnesium (in terms of $\mathrm{MgO}$ $1,241 \%$ ), a little less number of silicon (in terms of $\mathrm{SiO} 2$ $0,644 \%$ ), sulphur (in terms of SO2-0, $57 \%$ ). The data catalyst obtained from the comparison, it is seen that in the composition of the $\mathrm{X} 1$ catalyst includes a significant quantity of kalium and lanthanides, which are considered to be promoters of the catalysis EOC [15]. For the MEDC-B catalyst has been detected the presence a little less number of magnesium, which is also considered a promoter, but the content of lanthanides have been fixed in minor amounts.

Thus, it is known that the MEDC-B catalyst works a lot better in the process of producing 1.2-DCE by reaction of EOC [16].

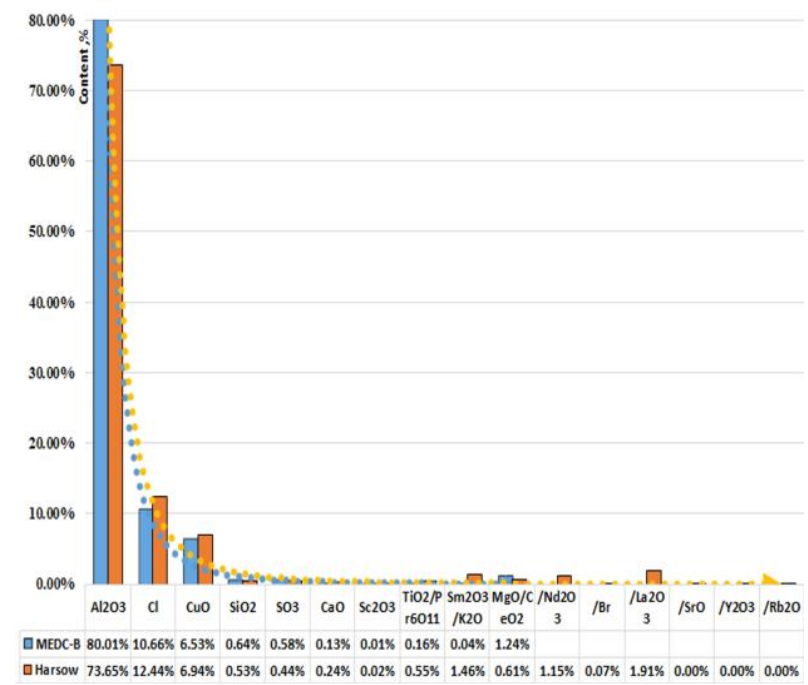

Fig. 12: Oxide Content of the Catalysts Xone and MEDC-B of the EOC (X-Ray Fluorescence Energy Dispersion Spectroscopy EDX-7000 "Simatsu" Oxides and Elements -Na-U).

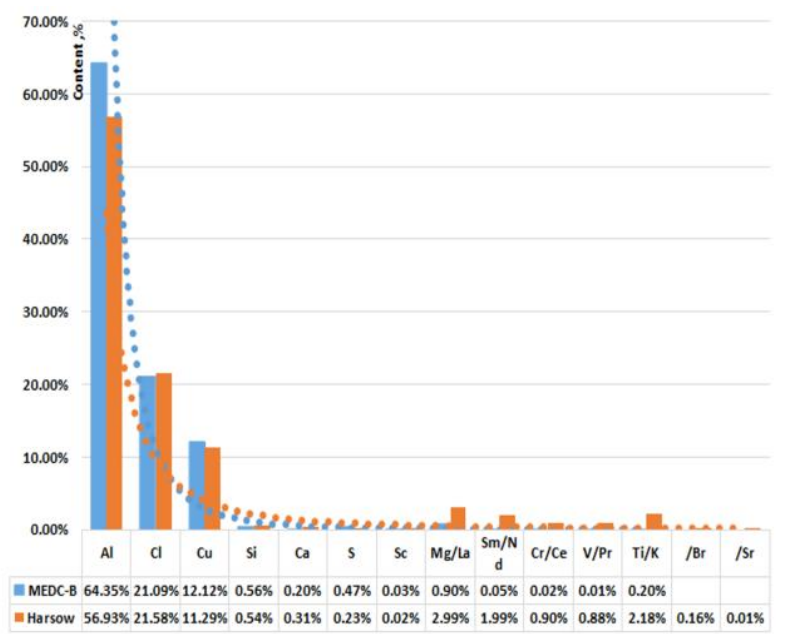

Fig. 13: Elements Content of the Catalysts X1 and MEDC-B of the EOC (X-Ray Fluorescence Energy Dispersion Spectroscopy EDX-7000 "Simatsu" Elements -Na-U).

That is why lanthanides don't have determinant influence on the process of $\mathrm{EOC}$, but structure of the catalyst surface and the nature of the interaction of the catalyst carrier $\gamma-\mathrm{Al}_{2} \mathrm{O}_{3}$ and the active phase of the catalyst copper chloride $\mathrm{CuCl}_{2-1}$ has much more 
meaning [17]. As for silicon and sulphur as already mentioned the silicon enters to catalyst structure with $\mathrm{HCl}$ and sulfur with $\mathrm{CuCl}_{2}$.

\subsection{Thermoelectric e-raster microscopy}

Figures 14 and 15 show electron micrographs of samples of active phases of $\mathrm{CuCl}_{2}$ and $\mathrm{H}_{2} \mathrm{CuCl}_{4}$ from catalysts (EOC) of the MEDC$\mathrm{B}$ and $\mathrm{X} 1$ Harshow brands, the comparison of which shows a different structure of the surface and structures of active phases. So with microfoto of the active phase of $\mathrm{H}_{2} \mathrm{CuCl}_{4}$ in Fig. 14 it can be concluded that it is mainly amorphous. At the same time, as for the active phase $\mathrm{CuCl}_{2}$ (Fig. 15) is characterized by a crystalline structure, which is supported by literary data [18].

After detailed analysis of the microphotographs of the marker X1 (fig.16 (left)), it is evident that the size of the particles of round particles varies in the range of 34.19-19.17 $\mu \mathrm{m}$. From the selected medium sinter, a particle $(70.49 \mu \mathrm{m})$ with an increase in (Fig. 16 (right) and 17 (left)) shows that the active phase of the catalyst $\left(\mathrm{H}_{2} \mathrm{CuCl}_{4}\right)$-light lines and strips of lower optical density in photo.17 (left) (cluster) is on the boundary of the phase separation with a carrier $\gamma-\mathrm{Al}_{2} \mathrm{O}_{3}$, But even a strong increase of the cluster to 25000h in Fig. 17 (right) does not provide discrete parts of a separate active phase $\left(\mathrm{H}_{2} \mathrm{CuCl}_{4}\right)$ with a size of $0.46-2.67 \mu \mathrm{m}$.

On the catalyst surface X1(Harshow) (fig.16, 17) copper chlorides have the form of uniformly distributed throughout the volume of the carrier and the surface of the $\gamma-\mathrm{Al}_{2} \mathrm{O}_{3}$ catalyst of amorphous regions $-\mathrm{H}_{2} \mathrm{CuCl}_{4}$ (Fig.14). At the same time, a separate cluster immobilized crystalline structure of active phase $\mathrm{CuCl}_{2}$ (fig.15) is visible on the surface of the catalyst MEDC-B (fig.18, 19), which differs from the composition of the carrier $\gamma-\mathrm{Al}_{2} \mathrm{O}_{3}$, which is very well seen in a micrograph with a strong increase in the photo (fig.18 (right)).

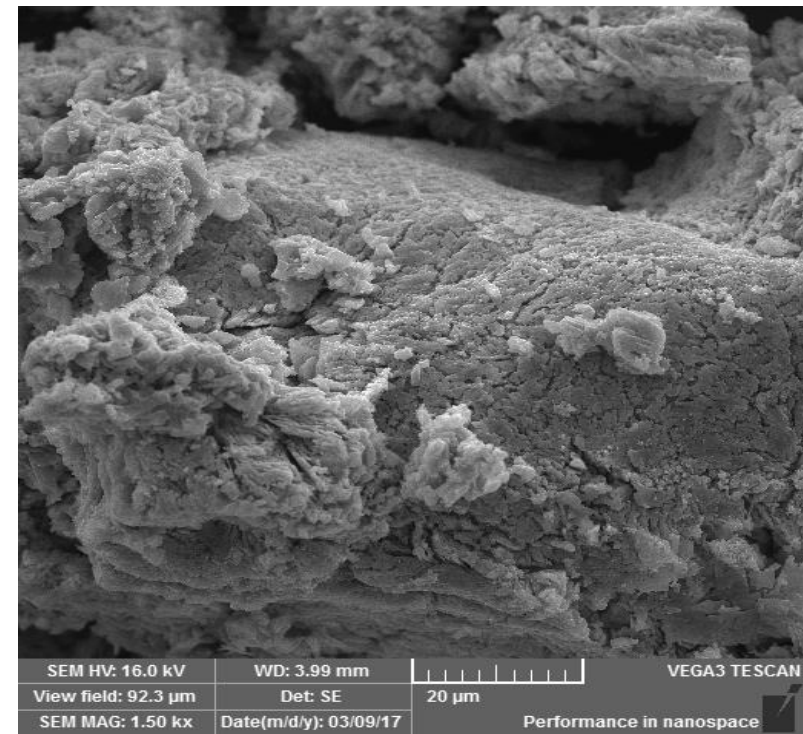

Fig. 14: Electron Microscopic Photo of the Active Phase of the Catalys OCE $\mathrm{H}_{2}$ cucl (Thermoelectric E-Raster Microscopy - VEGA 3 NT SCAN, Magnification: 1500X)

The size of these clusters varies in the range (10-14 $\mu \mathrm{m} \times 12-16$ $\mu \mathrm{m})$ (fig.18 (right)), and the size of the immobilized crystallites is 0.5-1.5 $\mu \mathrm{m}$ (Fig. 19).

If we calculate the concentration of these clusters on the surface of a carrier $(100 \mu \mathrm{m}$, photo (fig.18 (left)), then the average cluster of the active phase of $\mathrm{CuCl}_{2}$ has dimensions of $14.04 \times 15.87 \mu \mathrm{m}$ (Fig. 18 (right)). In this case, the ratio of the surface area of the particle carrier with the size $100 \mu \mathrm{m}$ (Fig. 18 (left)) $\mathrm{S}=31400$ $\mu \mathrm{m}^{2}$, while the area of the immobilized active phase of the $\mathrm{CuCl}_{2}$ cluster with dimensions of $14.04 \times 15.87 \mu \mathrm{m}$ (fig. 18 (right)) S1 = $222.81 \mu \mathrm{m}^{2}$.

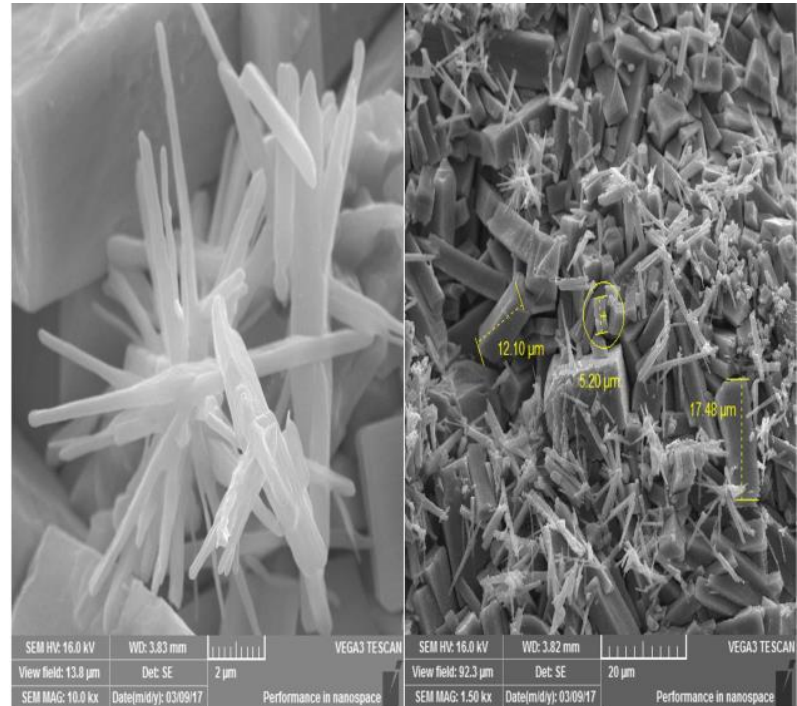

Fig. 15: Electron Microscopic Photo of the Active Phase Cucl of the Catalyst OCE (Thermoelectric E-Raster Microscopy - VEGA 3 NT SCAN, Magnification: 1500-10000X).

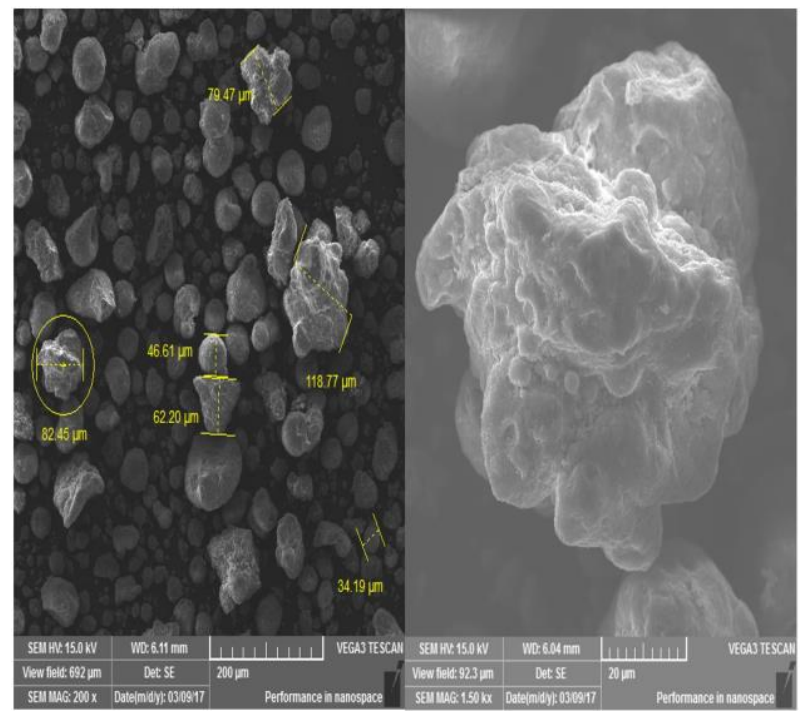

Fig. 16: Electron Microscopic Photo of the X1 - Catalyst OCE (ThermoElectric E-Raster Microscopy - VEGA 3 NT SCAN, Magnification: 200$1500 \mathrm{X})$

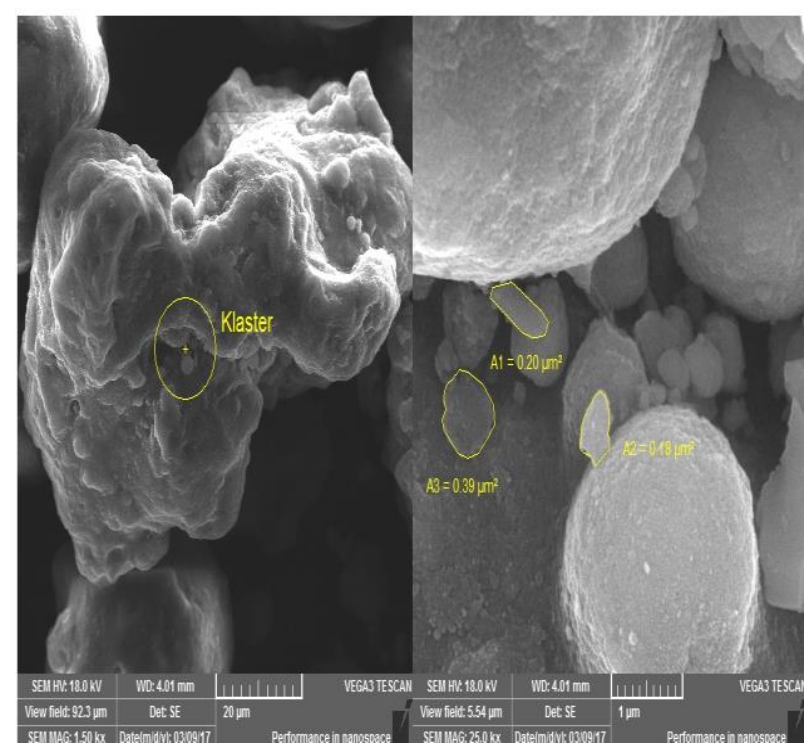

Fig. 17: Electron Microscopic Photo of the X1 - Catalyst OCE (ThermoElectric E-Raster Microscopy - VEGA 3 NT SCAN Magnification: 150025000X) 


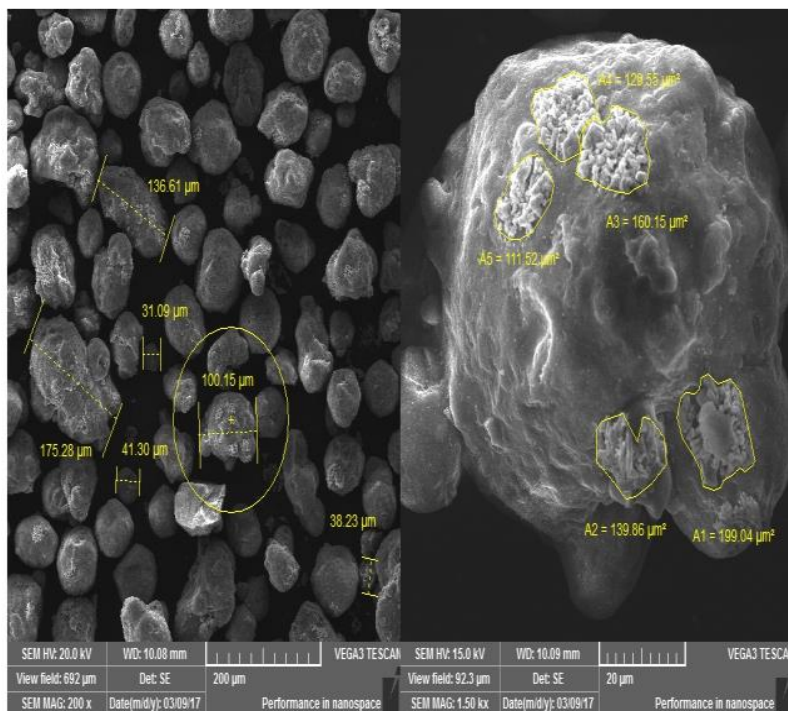

Fig. 18: Electron Microscopic Photo of the MEDC-B -Catalyst OCE (Thermoelectric E-Raster Microscopy - VEGA 3 NT SCAN, Magnification: $200-1500 \mathrm{X}$ )

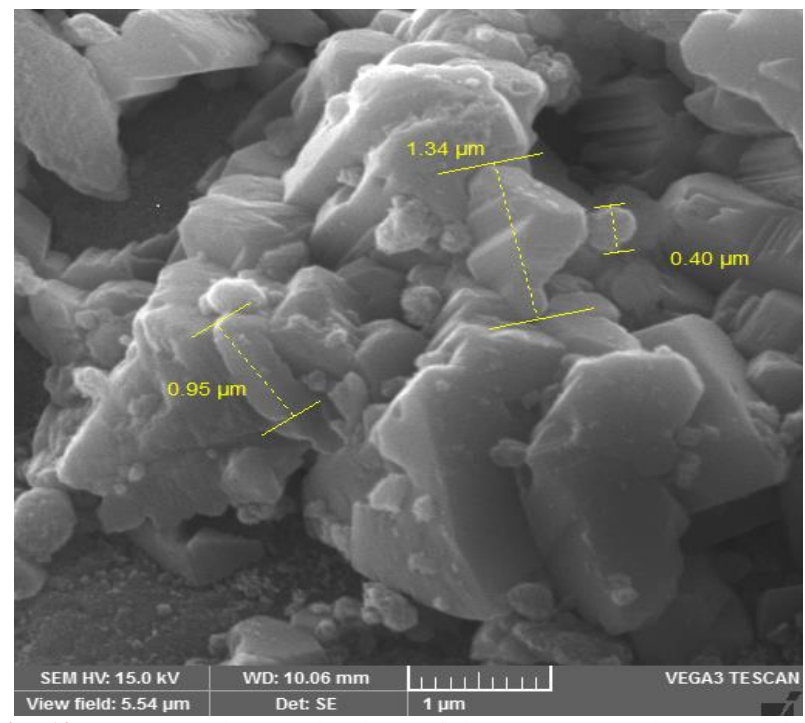

Fig. 19: Electron Microscopic Photo of the Medc-B Catalyst Oce (Ther mos-Electric E-Raster Microscopy - Vega 3 Nt Scan Magnification: 15002500x).

After the uniform distribution of these clusters, with the size of the crystals $0.4-1.33 \mu \mathrm{m}$ (fig.19) on the surface of the carrier particles taking into account the same distance between clusters is obtained theoretically, on the surface can be $\mathrm{X}=\mathrm{S} / 2 \mathrm{~S} 1=70 \mathrm{pcs}$. Clusters, but in practice we can only see 5-7 clusters (fig.18 (right)), which is $6 \mathrm{~S} 1 / \mathrm{S}=4-6 \%$, which is close to the percentage of copper compounds in the MEDC-B catalyst (fig. 8-9).

We can see immobilized (selected) catalyst clusters - fairly ordered form of compounds of copper chlorides with a carrier on the surface of the catalyst MEDC-B (fig 19). Oxyclorination reaction passes is more actively and mainly selectively at such active centers. When we compare all of the microphotographs, we can see copper chlorides (Fig. 14-15) which are predominantly in a different form on the surface of the catalysts.

Taking into account the foregoing, it can be argued that the structure of active centers on the surface of the catalysts X1(Harshow) and MEDC-B is confirmed, and determines the mechanism of the reaction of EOC for each of the selected catalysts differ from each other and was described by us earlier [6].

Thus the definition nanostructure catalyst surface OCE determine the conversion of raw materials, as well as yield and selectivity of the process and lead to fewer byproducts, organochlorine waste that will improve the environmental and economic component of the industrial process in the production of 1.2-DCE and VCM in global scale[14].

\section{Conclusions}

The following conclusions can be drawn.

1) The structure and composition of active catalyst centers $\left(\mathrm{CuCl}_{2}, \mathrm{H}_{2} \mathrm{CuCl}_{2}\right.$, and $\left.\mathrm{H} 2 \mathrm{CuCl} 4\right)$ used for ethylene oxidative chlorination on the $\gamma-\mathrm{Al}_{2} \mathrm{O}_{3}$ and two types of catalysts $\mathrm{X} 1$ and catalyst MEDC-B were considered. It is shown that the active catalyst centers of $\mathrm{CuCl}_{2}$ MEDC-B differ in crystalline structure from the amorphous active phase $\mathrm{H}_{2} \mathrm{CuCl}_{2}$, $\mathrm{H}_{2} \mathrm{CuCl}_{4} \mathrm{X} 1$. The content of the main components of cuprum and chlorine (96-97\%) is slightly lower than in the active phase of $\mathrm{H}_{2} \mathrm{CuCl}_{2}, \mathrm{H}_{2} \mathrm{CuCl}_{4}$ on the $\mathrm{X} 1$, where their amount exceeds $99 \%$, which affects their activity, in the composition of the active catalyst centers of $\mathrm{CuCl}_{2}$ for MEDC-B in the reaction of EOC.

2) On the surface of catalyst $X 1$, copper chlorides have the form of a homogenized catalyst of amorphous regions$\mathrm{H}_{2} \mathrm{CuCl}_{4}, \mathrm{H}_{2} \mathrm{CuCl}_{2}$, uniformly distributed throughout the volume and on the surface of the carrier of $\gamma-\mathrm{Al}_{2} \mathrm{O}_{3}$. At the same time, on the surface of the catalyst MEDC-B, the active centers have a separate cluster immobilized crystal-like structure of the active phase, which differs from the composition of the carrier $\gamma-\mathrm{Al}_{2} \mathrm{O}_{3}$, and in the area of $150-250 \mu \mathrm{m}^{2}$, and does not exceed by number $\left(4-6 \% \mathrm{Cu}^{+1,2}\right)$ with nanostructured sizes $(400-1340 \mathrm{~nm})$, which is close to the percentage of coupling compounds in the MEDC-B catalyst.

3) Based on the above described cluster immobilized structure and the structure of the surface layer of the catalyst of the MEDC-B brand can be concluded that it is more active, selective and easily renewable for the industrial process of oxychlorination of ethylene in 1,2-dichloroethane, compared with the catalyst EOC brand X1 (Harshow).

\section{References}

[1] Moscow-Kalush. Technological Standards at Plant of Vinyl Chloride Production; 2006.

[2] Flid M.R, Treger YA: Vinyl Chloride: Chemistry and Technology. First edition. Moscow, Russia: "Kalvis"; 2008. P.214-372.

[3] Kurta S.A. Improvement of technological processes of vinyl chloride production: Dissertation submitted to fulfill the requirement for the degree of Doctor of Science with specialization of 05.17.04 - technology of products of organic synthesis. National University "Lviv Polytechnics”, Lviv; 2015.

[4] Flid M.R, Kurlyandskaya II, Dmitriev YuK, Babotina MV. Oxidation reaction in the ethylene oxidative chlorination process. In Principles and Methods for Accelerated Catalyst Design and Testing. Netherlands: Kluwer Academic Publishers; 2002.

[5] Flid M.R. Resources-economy, balance by chlorine technology to obtain of the vinyl chloride from primary goods ethane-ethylene: Doctoral Dissertation in Technical Sciences: Research institute "Synthesis"; Moscow; 2002.

[6] Kurta S.A., Mykytyn I.M, Tatarchuk T.R. Structure and the catalysis mechanism of oxidative chlorination in nanostructural layers of a surface of alumina. Nanoscale esearch Letters. 2014; 9:1.

[7] Garilli M, Carmello D, Cremaschi B, Leofanti G, Padovan M, Zecchina $\mathrm{A}$, et al. Copper species in $\mathrm{CuCl}_{2} / \gamma-\mathrm{Al}_{2} \mathrm{O}_{3}$ catalyst for ethylene oxychiorination Studies in Surface Science and Catalysis. 2000; 130. p. 1817-1822.

[8] Leofanti G, Padovan M, Garilli M, Carmello D, Marra GL, Zecchina A, et al. Alumina-Supported Copper Chloride. Effect of Aging and Thermal Treatments Journal of Catalysis. 2000; 189:1. p. 105116.

[9] Leofanti G, Padovan M, Garilli M, Carmello D, Zecchina A, Spoto G, et al. Alumina-Supported Copper Chloride: 1. Characterization of Freshly Prepared Catalyst. Journal of Catalysis. 2000; 189:1. p. 91-104.

[10] Kurta SA, Tatarchuk TR, Mykytyn IM. Crystal-oxidechemical mechanism of catalysis of oxidative chlorination of 
ethylene. The Ukrainian Chemical Journal. ISSN 0041-6045, View. IZNKh NAS of Ukraine Kiev.2013; 79:6. p. 101-106.

[11] Kurta SA, Mykytyn IM, Khaber MV. Influence of regeneration conditions on the activity of the catalyst for oxidative chlorination of ethylene. Russian Journal of Applied Chemistry. Russia. 2005; 76:7. p.1110-1113

[12] Gianolio D, Lamberti C, Muddada NB, Olsbye U. Doped$\mathrm{CuCl}_{2} / \mathrm{Al}_{2} \mathrm{O}_{3}$ catalysts for ethylene oxychlorination: Influence of additives on the nature of active phase and reducibility. Nuclear Instruments and Methods in Physics Research Section B: Beam Interactions with Materials and Atoms. 2012; 284:1. p. 53-57.

[13] Rout KR, Baidoo MF, Fenes E, Zhu J, Chen D, Fuglerud T. Understanding of potassium promoter effects on oxychlorination of ethylene by operando spatial-time resolved UV-vis-NIR spectrometry. Journal of Catalysis. 2017; 352. p. 218-228.

[14] Rouco AJ. Low-Temperature Ethylene Oxyhydrochlorination: Effects of Supports and Promoters on the Mobilities of Active Species in $\mathrm{CuCl}_{2}$ Catalysts. Journal of Catalysis. 1995; 157:2. p. 380-387.

[15] Kurta SA, Mykytyn IM, Kurta OS. The structure of the active centers on the catalyst surface $\mathrm{CuCl}_{2} / \gamma-\mathrm{Al}_{2} \mathrm{O}_{3}$. Phys Chem Solids State. 2008; 9:577. p. 582.

[16] Kurta SA. Catalysis of ethylene oxyclorination into 1, 2diclorethane in the presence of $\mathrm{CuCl}_{2} / \mathrm{CuCl}$ active centres on the surface of $\gamma-\mathrm{Al}_{2} \mathrm{O}_{3}$. CHEMISTRY \& CHEMICAL TECHNOLOGY/ISSN: 1996-4196. Lviv Polytechnic 2012, 1:1-8.

[17] Kurta, SA. Investigating active centers ofindustrial catalysts for the oxidative chlorination of ethylene on a $\gamma-\mathrm{Al}_{2} \mathrm{O}_{3}$ surface. Catalysis in Industry. Ed. "Kalvis" Moscow, Russia. 2011; 2. p. 15-21.

[18] Lamberti C, Prestipino $\mathrm{C}$ and co-author. The $\mathrm{CuCl}_{2} / \mathrm{Al}_{2} \mathrm{O}_{3}$ catalyst investigated in interaction with reagent. Int.J.Mol.Sci.2001; 2. p. 230-245.

[19] Thakurdesai PA, Kole PL \& Pareek RP (2004), Evaluation of the quality and contents of diabetes mellitus patient education on Internet. Patient Education and Counseling 53, 309-313. 